\title{
A novel mitochondrial protein is required for cell wall integrity, auxin accumulation and root elongation in Arabidopsis under salt stress
}

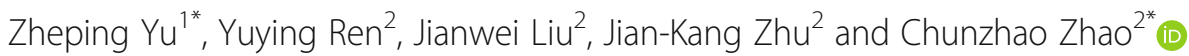

\begin{abstract}
Maintenance of root elongation is beneficial for the growth and survival of plants under salt stress, but currently the cellular components involved in the regulation of root growth under high salinity are not fully understood. In this study, we identified an Arabidopsis mutant, rres1, which exhibited reduced root elongation under treatment of a variety of salts, including $\mathrm{NaCl}, \mathrm{NaNO}_{3}, \mathrm{KCl}$, and $\mathrm{KNO}_{3}$. RRES1 encodes a novel mitochondrial protein and its molecular function is still unknown. Under salt stress, the root meristem length was shorter in the rres 1 mutant compared to the wild type, which was correlated with a reduced auxin accumulation in the mutant. Reactive oxygen species (ROS), as important signals that regulate root elongation, were accumulated to higher levels in the rres1 mutant than the wild type after salt treatment. Measurement of monosaccharides in the cell wall showed that arabinose and xylose contents were decreased in the rres 1 mutant under salt stress, and application of boric acid, which is required for the crosslinking of pectic polysaccharide rhamnogalacturonan-II (RG-II), largely rescued the root growth arrest of the rres1 mutant, suggesting that RRES1 participates in the maintenance of cell wall integrity under salt stress. GUS staining assay indicated that the RRES1 gene was expressed in leaves and weakly in root tip under normal conditions, but its expression was dramatically increased in leaves and roots after salt treatment. Together, our study reveals a novel mitochondrial protein that regulates root elongation under salt stress via the modulation of cell wall integrity, auxin accumulation, and ROS homeostasis.
\end{abstract}

Keywords: Salt stress, Auxin, Reactive oxygen species, Plant cell wall, Arabidopsis

\section{Introduction}

Salinity is one of the abiotic stresses that adversely affect plant growth and agricultural productivity worldwide. During the last three decades, the molecular mechanisms of salt stress response in plants have been extensively studied (Gong et al., 2020). The detrimental effects of salt stress on plant growth and development can be divided into three aspects: osmotic stress, ion

\footnotetext{
* Correspondence: yuzp@zaas.ac.cn; czzhao@psc.ac.cn

${ }^{1}$ Institute of Horticulture, Zhejiang Academy of Agricultural Sciences,

Hangzhou 310021, China

${ }^{2}$ Shanghai Center for Plant Stress Biology, CAS Center for Excellence in

Molecular Plant Sciences, Chinese Academy of Sciences, Shanghai 200032, China
} \\ Springer}

toxicity, and oxidative stress (Hasegawa et al., 2000; Roy et al., 2014; Hazman et al., 2015). After being exposed to high salinity, rapid elevation of ions surrounding root cells immediately triggers osmotic stress (Roy et al., 2014). Osmotic stress affects many developmental and physiological processes, including cell volume and turgor pressure, cell dehydration, cell division and expansion, and photosynthesis rate (Gong et al., 2020). The second phase is ionic stress and it occurs when ions are transported into plant cells. High concentration of $\mathrm{Na}^{+}$in the cytoplasm is toxic to enzymes and thus causes cell growth arrest and even cell death (Hasegawa et al., 2000; Gong et al., 2020). To cope with the toxic effect, 
excessive ions need to be extruded from the cytoplasm to the outside of cells or compartmentalized into the vacuole. Meanwhile, maintenance of $\mathrm{Na}^{+}$and $\mathrm{K}^{+}$homeostasis is critical for attenuating the adverse effect of $\mathrm{Na}^{+}$ (Zhu, 2003). High salinity also leads to the production of excessive reactive oxygen species (ROS), which triggers oxidative stress in plant cells (Zhu et al., 2007; Hazman et al., 2015). Appropriate concentration of ROS can be used as important signaling molecules in response to salt stress (Yang et al., 2014; Yang \& Guo, 2018). However, excessive accumulation of ROS causes oxidative stress, leading to damages of DNA, proteins, and lipids (Moldovan \& Moldovan, 2004; Genisel et al., 2014; Golldack et al., 2014).

Root is essential for plants to uptake water and nutrients to support the growth and development of aerial organs. Under salinity conditions, root is the first organ that suffers stress. High salinity severely inhibits root growth in a vast majority of plant species, including cotton (Zhong and LÄUchli, 1993), rice (Lin \& Kao, 1996), Arabidopsis (Wu et al., 1996), maize (Rodriguez et al., 1997), soybean (Phang et al., 2008), wheat (Rahnama et al., 2011), and barley (Shelden \& Roessner, 2013). High salinity affects primary root growth by inhibiting cell division and cell expansion (Gong et al., 2020), and auxin signaling pathway is shown to be involved in the regulation of these processes (Tomas et al., 2020). Under salt stress, auxin level and the expression of auxin transporters are reduced, which results in reduced root meristem activity and primary root growth inhibition (Liu et al., 2015). Therefore, understanding of the regulatory mechanisms of auxin signaling under salt stress will be useful for future biotechnological application to increase salt tolerance in plants (Tomas et al., 2020).

In plants, cell wall not only determines cell expansion and growth but also provides a mechanical protection against abiotic stress (Wolf et al., 2012). Accumulating evidence indicates that maintenance of cell wall integrity is critical for salt tolerance in plants. Many mutants that are disrupted in cell wall biosynthesis, modification, or perception exhibit an increased sensitivity to salt stress. Mutation of SOS5 gene, which encodes an apoplastic arabinogalactan protein (AGP)-like protein, results in a severe root growth arrest under salt stress (Shi et al., 2003). CESA6 encodes one of the cellulose synthases that are essential for cellulose biosynthesis. Due to abnormal cellulose biosynthesis, the cesa 6 mutant displays severe root growth inhibition and cell swelling under salt stress. In agreement with this finding, it was reported that cellulose synthase-like protein SOS6 and companion of cellulose synthase 1 and 2 (CC1 and CC2) are required for root and hypocotyl elongation under salt stress (Zhu et al., 2010; Endler et al., 2015). Our recent study reported that MUR4, which is required for UDP-
Ara biosynthesis, is involved in the maintenance of cell wall integrity under salt stress. The MUR4 gene mutation leads to abnormal cell-cell adhesion and reduced root elongation under salt stress (Zhao et al., 2019). To avoid the disruption of cell wall integrity during cell expansion and in response to environmental stresses, plants have developed various sensors to continuously monitor cell wall status. FERONIA (FER), a plasmamembrane localized receptor kinase, is considered as one of the cell wall integrity sensors. Mutation of FER gene results in enhanced leaf bleaching and root cell swelling under salt stress, and it was proposed that FER participates in the regulation of cell wall repair under salt stress via a $\mathrm{Ca}^{2+}$-mediated signaling pathway (Deslauriers \& Larsen, 2010; Feng et al., 2018). In this study, through a high-throughput genetic screen of Arabidopsis mutants that are hypersensitive to salt stress, we identified a mutant that displayed slower root elongation under salt stress compared with the wild type plants. Analysis of monosaccharides showed that arabinose and xylose contents in the cell wall were reduced in the mutant after salt treatment, and application of exogenous boric acid largely rescued the root growth inhibition of the mutant, supporting the importance of cell wall integrity in salt tolerance. Moreover, ROS and auxin homeostasis were also disrupted in the mutant under salt stress.

\section{Results}

\section{RRES1 is required for the regulation of root elongation} under salt stress

To identify genes that participate in the regulation of salt tolerance, we performed a genetic screen for Arabidopsis mutants that were generated by EMS-mediated mutagenesis (Fujii et al., 2011; Wu et al., 1996). Multiple mutants that showed reduced root elongation under high salinity were identified, and here we report one of these mutants, named 19-1. The 19-1 mutant showed slightly reduced root elongation when grown on MS medium, but exhibited strong root growth inhibition when grown on MS medium supplemented with $100 \mathrm{mM} \mathrm{NaCl}$ (Fig. S1a and b). To identify mutated gene in the 19-1 that was responsible for salt-hypersensitivity, we backcrossed 19-1 with its parent plant and performed bulk segregant analysis (BSA) using $\mathrm{F}_{2}$ population. Mapping result revealed a significant peak at the end of the second chromosome (Fig. S1c). By searching for all the mutations in this region, we found a C199T mutation in AT2G45320 gene, which led to a pre-mature stop at Gln67. AT2G45320 is a novel gene that has not been reported before. As this gene mutation led to reduced root elongation under salt stress, we designed it as RRES1 (Reduced Root Elongation under Salt Stress 1). Alignment of the protein sequence of RRES1 against the 
(a)

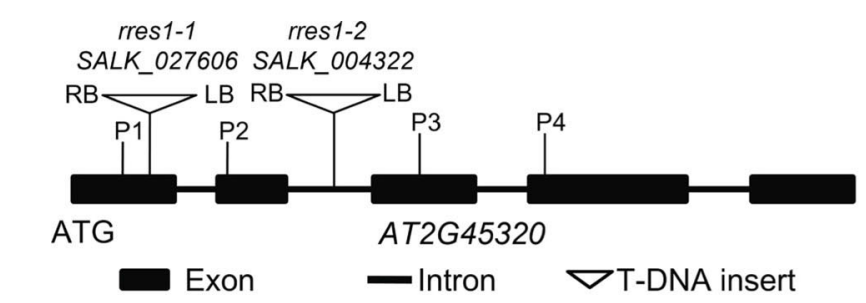

(c)

WT rres1-1 rres1-2 WT rres1-1 rres1-2

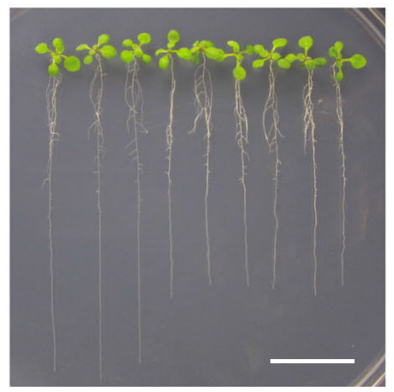

MS

(e)
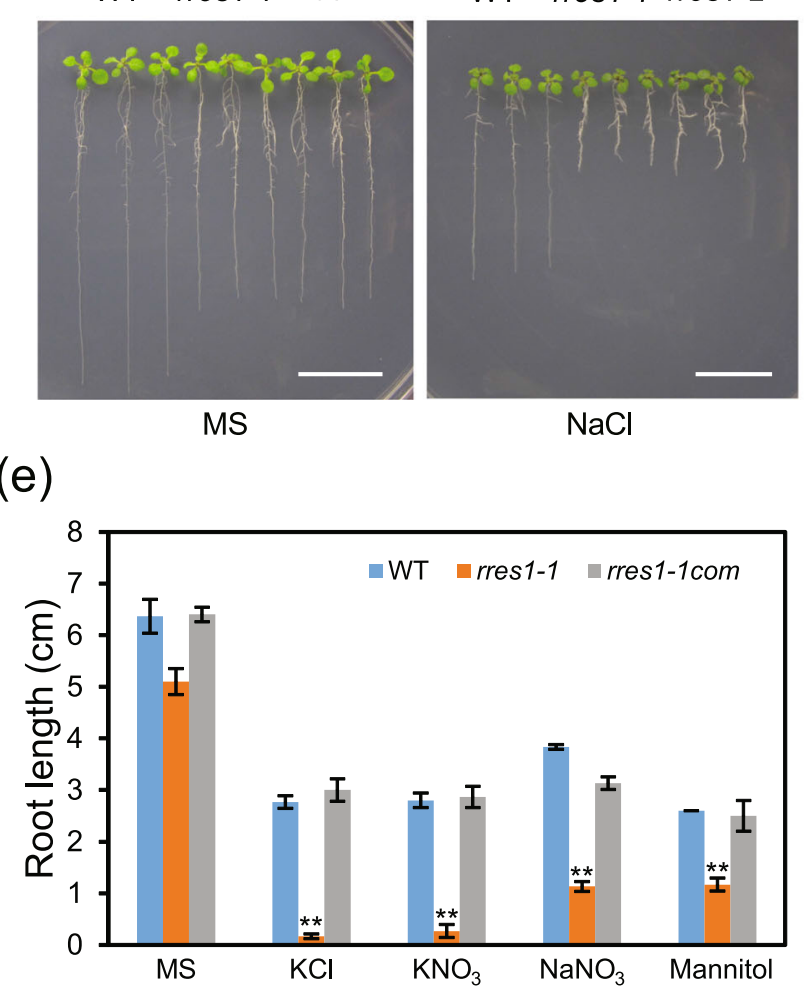

(b)

(d)

(f)

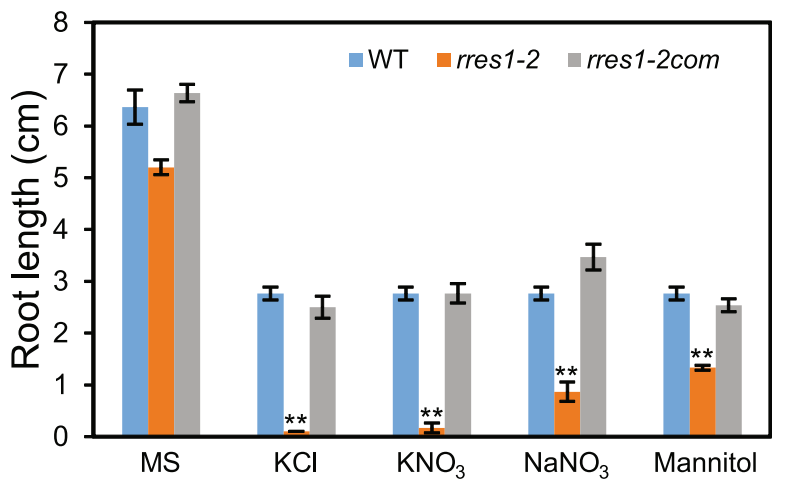

Fig. 1 RRES1 is required for the regulation of root elongation under salt stress. a Diagram of T-DNA insertion sites in two independent rres 1 mutant alleles. Triangles represent the T-DNA insertion sites in RRES1 gene. Black rectangles represent exon and black lines represent intron. $\mathbf{b}$ Transcript level of RRES1 in wild-type, rres1-1, and rres1-2 was evaluated by RT-PCR. ACTIN gene was used as an internal control. c Phenotype of the wild type, rres1-1 and rres1-2 grown on Murashige and Skoog (MS) media supplemented with or without $100 \mathrm{mM} \mathrm{NaCl}$. Scale bar = $2.5 \mathrm{~cm}$. $\mathbf{d}$ Quantification of root length of the wild type and rres 1 mutants. Five-day-old seedlings were transferred to MS or MS $+100 \mathrm{mM} \mathrm{NaCl}$ media and grown for 7 days, and the length of newly developed roots was measured. Values indicate means \pm SD $(n=5)$. Asterisks indicate statistically significant differences ${ }^{* *} p<0.01$ by Student's $t$ test). e-f Quantification of root length of the wild type, rres 1 mutant and complementation lines after being transferred to MS media supplemented with $100 \mathrm{mM} \mathrm{KCl}, 80 \mathrm{mM} \mathrm{KNO}_{3}, 80 \mathrm{mM} \mathrm{NaNO}_{3}$, or $0.5 \mathrm{M}$ mannitol for 7 days. Asterisks indicate statistically significant differences (** $p<0.01$ by Student's $t$ test)

Arabidopsis database showed that the Arabidopsis contains only one copy of RRES1. According to the Arabidopsis Information Resource (TAIR, http://arabidopsis. org) annotation, RRES1 is predicted to encode a polyphosphatidylinositol phosphatase. However, alignment of this protein against the protein database in the NCBI, the orthologs of RRES1 are annotated as nucleotidediphospho-sugar transferases.

To verify that RRES1 is the gene that is required for root growth under salt stress, we ordered two independent T-DNA insertion lines SALK_027606 and SALK_ 004322, named as rres1-1 and rres1-2, from the 


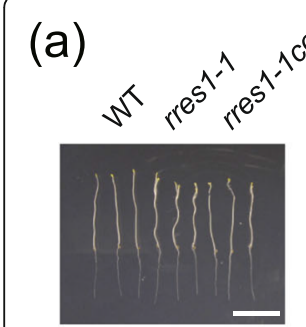

MS

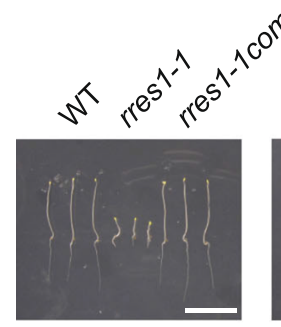

$\mathrm{KCl}$

(c)

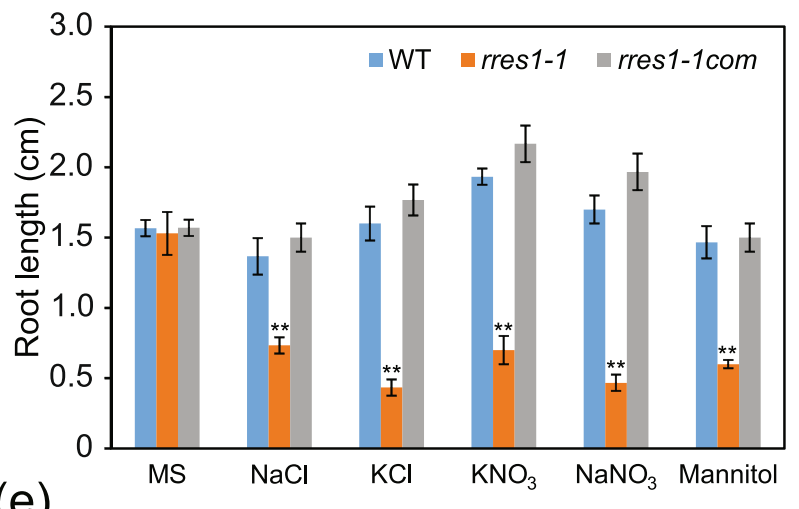

(e)
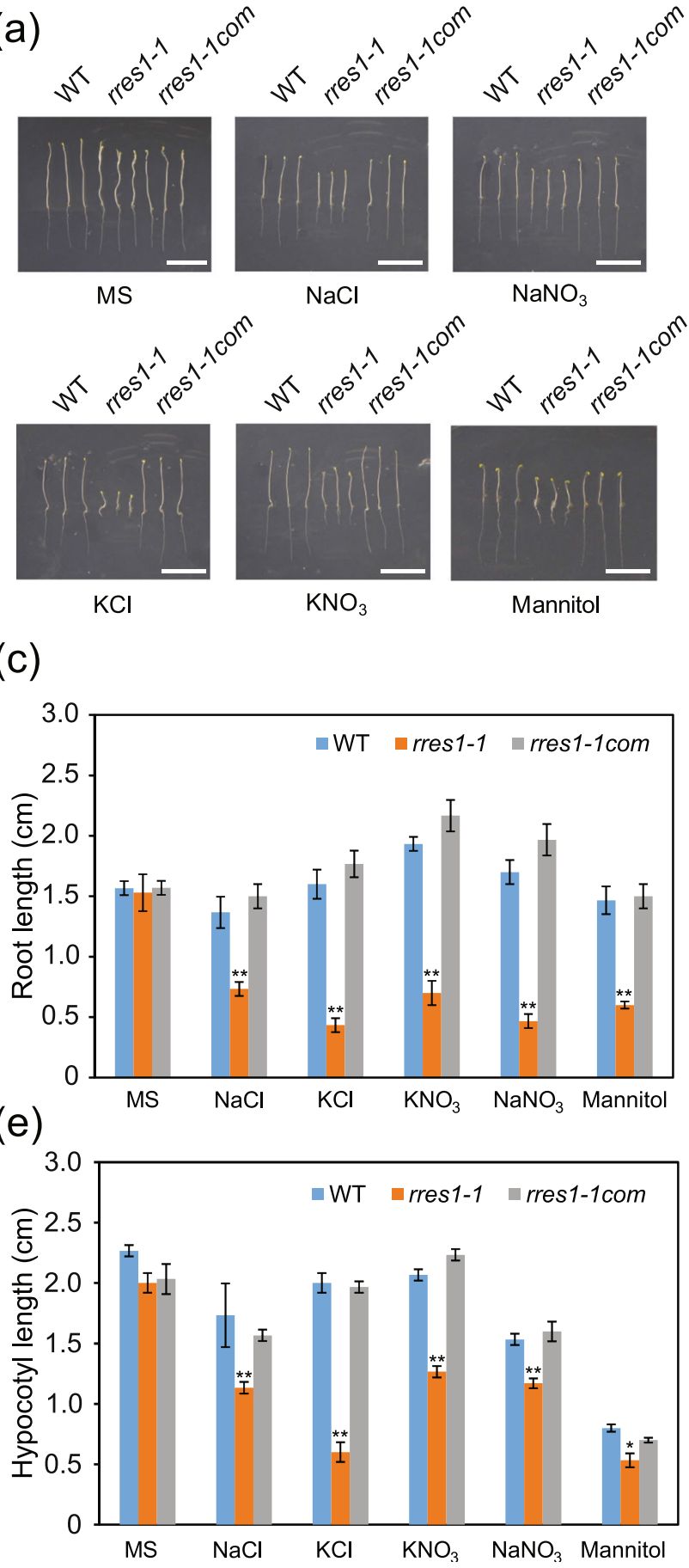

$\mathrm{NaCl}$

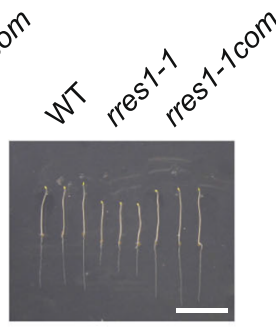

$\mathrm{NaNO}_{3}$

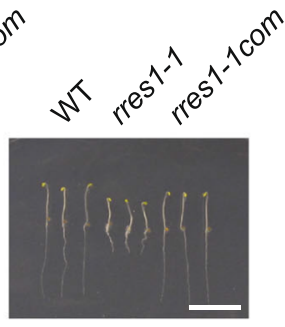

Mannitol

$\mathrm{KNO}_{3}$ (b)

(d)

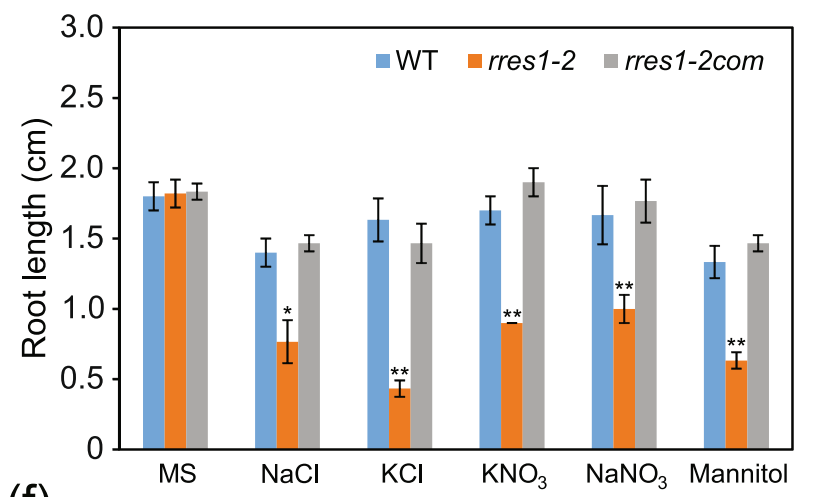

(f)

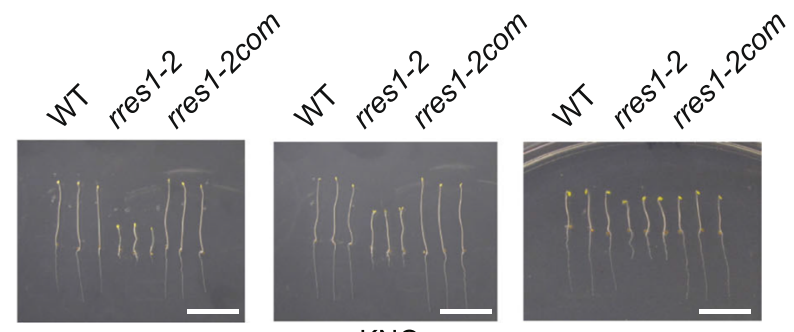

$\mathrm{KCl}$

$\mathrm{KNO}_{3}$

Mannitol
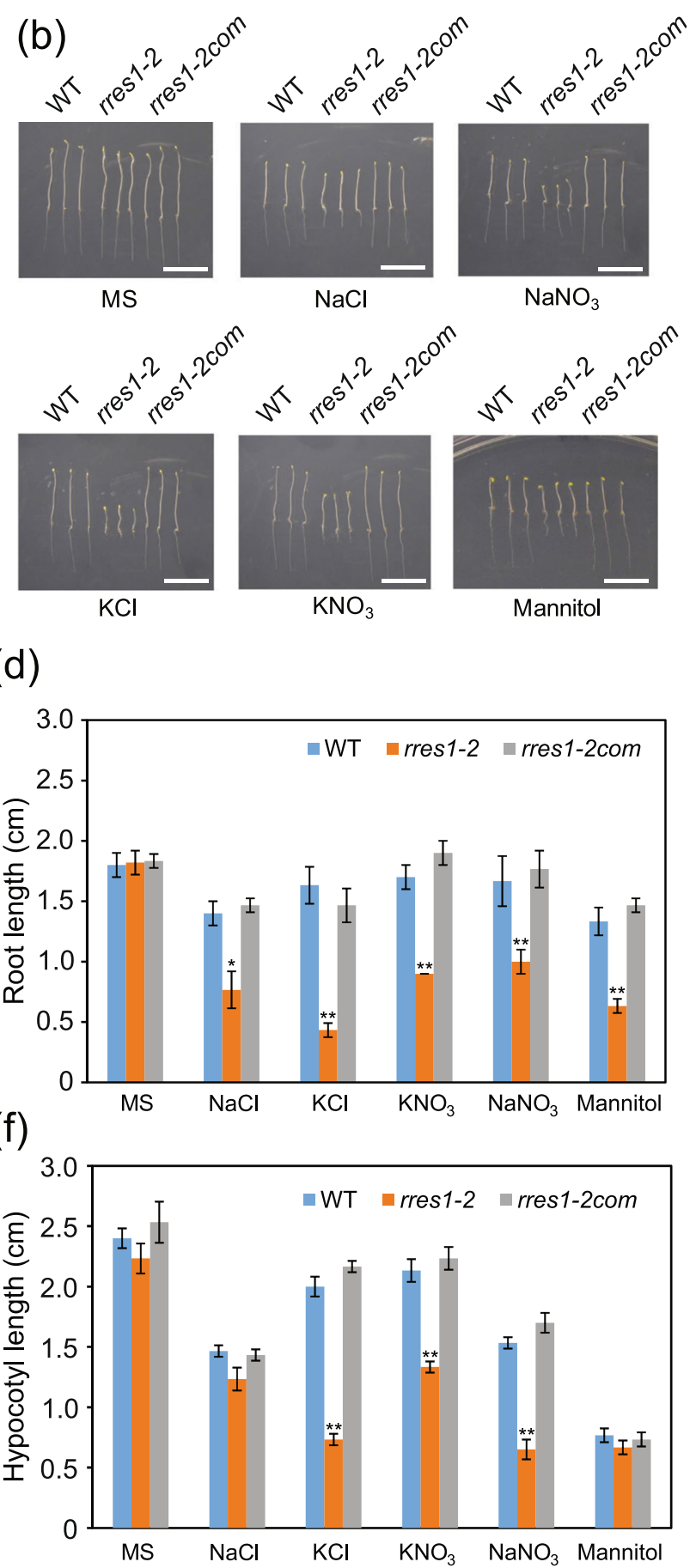

Fig. 2 rres 1 mutants exhibit reduced hypocotyl elongation under salt stress. a-b Phenotypes of the wild type, rres 1-1, rres 1-2, and complementation lines after being transferred to each medium and placed under dark conditions for 7 days. Scale bar $=1 \mathrm{~cm}$. $\mathbf{c}$-d Quantification of the hypocotyl length of each genotype shown in (a) and (b). Values indicate means \pm SD $(n=6)$. Asterisks indicate statistically significant differences $\left({ }^{*} p<0.05,{ }^{* *} p<0.01\right.$ by Student's $t$ test). e-f Quantification of the root length of each genotype shown in (a) and (b). Values indicate means $\pm \operatorname{SD}(n=6)$. Asterisks indicate statistically significant differences $\left({ }^{*} p<0.05,{ }^{*} p<0.01\right.$ by Student's $t$ test)

Arabidopsis Stock Center (ABRC). In these two lines, the T-DNAs were inserted in the first exon and second intron of the RRES1 gene, respectively (Fig. 1a). RT-PCR assay showed that the RRES1 gene expression was largely reduced in both the rres1-1 and rres1-2 mutant alleles (Fig. 1b). Both the rres1 mutants showed similar developmental phenotypes as the wild type, including normal rosette leave size, normal plant height, and normal 
(a)

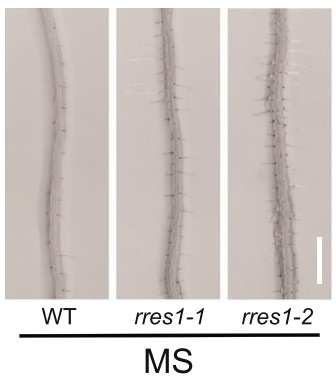

(c)

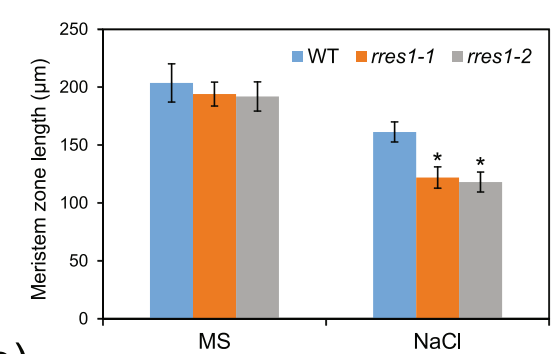

(e)

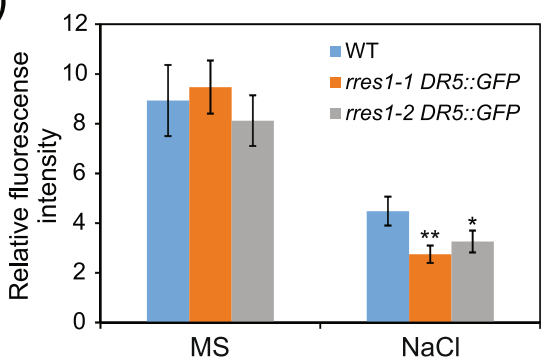

(b)

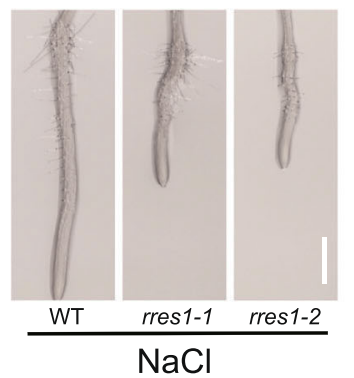

(d)

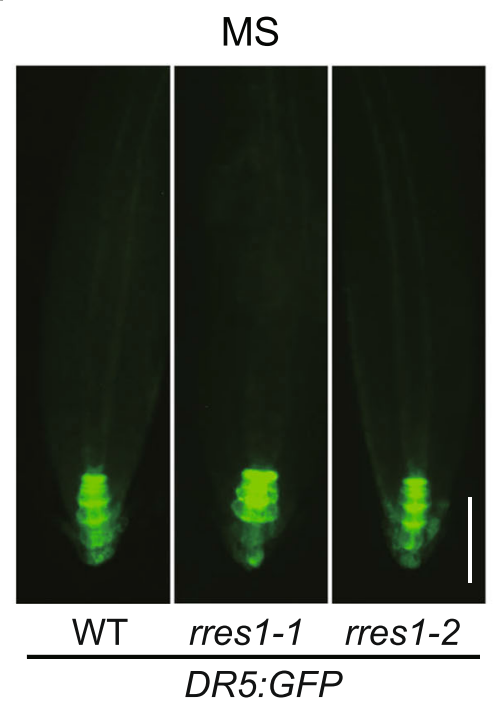

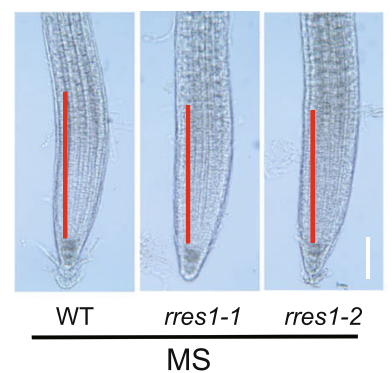

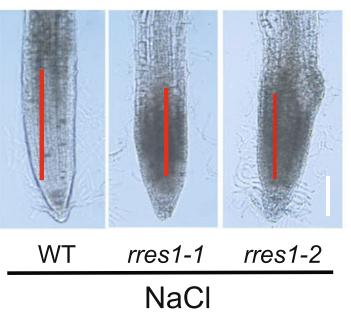

Fig. 3 Meristem zone length and auxin accumulation are reduced in rres 1 mutants under salt stress. a Root morphology of the wild type, rres 1-1, and rres 1-2 mutants after being transferred to MS media supplemented with and without $100 \mathrm{mM} \mathrm{NaCl}$ was detected by microscopy. Scale bar = $2 \mathrm{~mm}$. b Root meristem zone of the wild type, rres 1-1, and rres1-2 mutants after being transferred to MS media supplemented with and without $100 \mathrm{mM} \mathrm{NaCl}$. Red lines indicate meristem zones. Scale bar $=60 \mu \mathrm{m}$. c Quantification of the meristem length of each genotype after being transferred to MS media supplemented with or without $100 \mathrm{mM} \mathrm{NaCl}$. Values indicate means \pm SD $(n=5)$. Asterisks indicate statistically significant differences $\left({ }^{*} p<0.05\right.$ by Student's $t$ test). $\mathbf{d}$ Detection of the expression of DR5:GFP in the wild type and rres 1 mutants with or without salt stress treatment. Fluorescent signals were detected using a Carl Zeiss HBO100 microscope. Scale bar $=70 \mu \mathrm{m}$. e Quantification of the relative fluorescence intensity of the root tips shown in $(\mathbf{d})$. Values indicate means $\pm \operatorname{SD}(n=5)$. Asterisks indicate statistically significant differences $\left({ }^{*} p<\right.$ $0.05,{ }^{* *} p<0.01$ by Student's $t$ test)

flower size (Fig. S2a-c). However, the seed size of the rres 1 mutants was slightly larger than that of the wild type (Fig. S2d and e), while the silique length of the rres1 mutants was shorter than that of the wild type (Fig. S2f and g). To analyze the phenotype of these two rres $1 \mathrm{mu}-$ tant alleles under salt stress, five-day-old seedlings were transferred from MS medium to $100 \mathrm{mM} \mathrm{NaCl}$ medium. Similar to the 19-1, these two mutant alleles exhibited reduced primary root growth under salt stress (Fig. 1c, d), corroborating that RRES1 gene is required for salt tolerance in Arabidopsis. Moreover, transformation of RRES1pro:RRES1 genomic-GFP fully rescued the salt-hypersensitivity of the rres1-1 and rres1-2 mutants (Fig. S3).
We also tested the phenotype of the rres 1 mutants in response to other salts, including $80 \mathrm{mM} \mathrm{NaNO}, 100$ $\mathrm{mM} \mathrm{KCl}$, and $80 \mathrm{mM} \mathrm{KNO}_{3}$. Both the rres1-1 and rres 1-2 mutants were hypersensitive to $\mathrm{NaNO}_{3}$ (Fig. 1e and $\mathrm{f}$ ), which was similar to the phenotype of the seedlings grown on $\mathrm{NaCl}$ medium. On $\mathrm{KCl}$ and $\mathrm{KNO}_{3}$ media, the root elongation of the rres 1 mutants was also inhibited, and the growth arrest was much more severe than that under $\mathrm{NaCl}$ medium (Fig. 1e and f). Collectively, these results suggested that RRES1 is required for the response to multiple salts.

We then investigated the phenotype of the rres $1 \mathrm{mu}-$ tant under other abiotic stresses. After being transferred from MS medium to mannitol medium, both the rres1- 


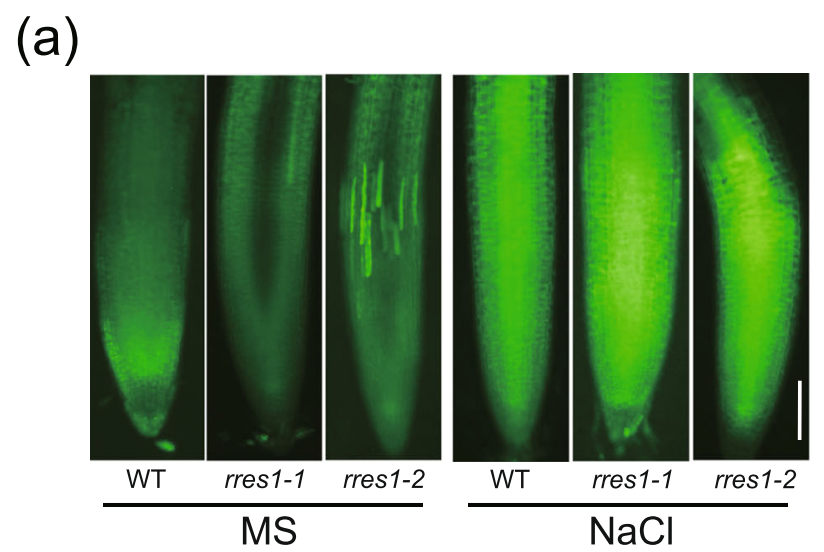

(c)

(b)
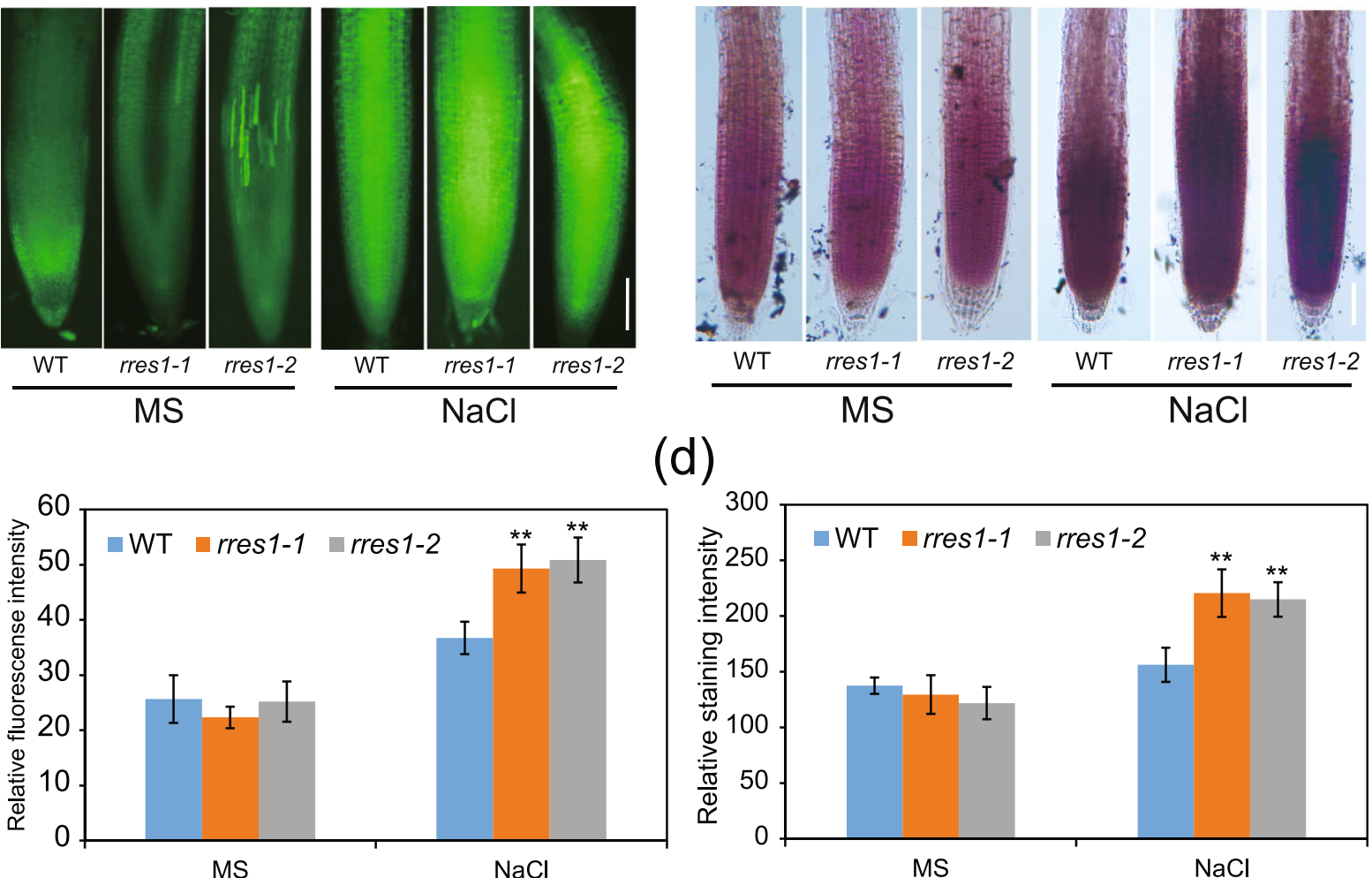

(d)

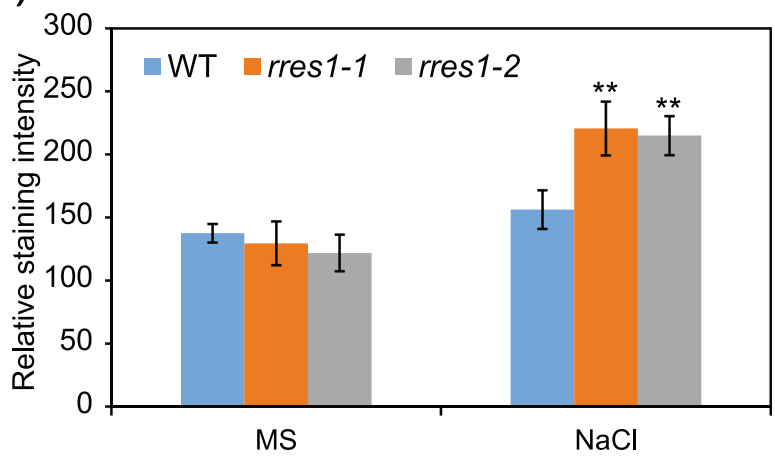

Fig. 4 rres 1 mutants exhibit increased ROS accumulation in roots. a 2', $7^{\prime}$-dichlorodihy-drofluorescein diacetate $\left(\mathrm{H}_{2} \mathrm{DCFDA}\right)$ staining of $\mathrm{H}_{2} \mathrm{O}_{2}$ in the roots of the wild type and rres 1 mutants grown on MS media supplemented with or without NaCl. Scale bar $=30 \mu \mathrm{m}$. $\mathbf{b}$ Relative fluorescence intensity of $\mathrm{H}_{2}$ DCFDA staining in the roots of the wild type and rres 1 mutants. Values indicate means $\pm \mathrm{SD}(n=5)$. Asterisks indicate statistically significant differences ( ${ }^{* *} p<0.01$ by Student's $t$ test). c DAB staining of $\mathrm{H}_{2} \mathrm{O}_{2}$ in the roots of the wild type and rres 1 mutants with or without $\mathrm{NaCl}$ treatment. Scale bar $=20 \mu \mathrm{m}$. d Relative DAB staining intensity in the roots of the wild type and rres 1 mutants. Values indicate means \pm SD $(n=5)$. Asterisks indicate statistically significant differences $\left({ }^{* *} p<0.01\right.$ by Student's $t$ test)

1 and rres1-2 mutants showed an obvious root growth arrest, although the inhibition degree was less severe than that under salt stress (Fig. 1e and f). The hypersensitivity of the rres1 mutants under osmotic stress could be restored in the complementation lines (Fig. 1e and $\mathrm{f}$ ), suggesting that RRES1 is also required for osmotic stress tolerance. To test the drought tolerance of the rres1 mutants, we first performed water loss assay using detached plants. The result showed that the rres1-1 and rres1-2 mutants displayed only slightly increased water loss rate compared with the wild type, implying that RRES1 is not important for drought stress tolerance (Fig. S4a). Consistently, drought tolerance assay performed in soil showed that no significant difference was observed between the wild type and rres 1 mutants after water deprivation (Fig. S4b).

\section{The rres 1 mutation results in reduced hypocotyl elongation under salt stress}

Plants that are hypersensitive to salt stress usually exhibit reduced seed germination under high salinity, so we observed the seed germination and cotyledon greening of the rres1 mutants after they were sown on $\mathrm{NaCl}$ medium. The rres1 mutants were indistinguishable from the wild type in terms of both seed germination and cotyledon greening under high salinity. Similarly, the rres1 mutants exhibited normal seed germination when grown on the media supplemented with mannitol or ABA. However, it was noted that both the rres1-1 and rres1-2 mutants exhibited decreased cotyledon greening rate when grown on ABA medium (Fig. S5), indicating that rres1 mutant is partially sensitive to ABA.

To determine whether the rres 1 mutation affects the growth of aerial tissues, we investigated hypocotyl elongation under salt stress. To this end, seeds were sown on $\mathrm{NaCl}$ medium and placed under dark conditions. After growth for 7 days, hypocotyl length was measured. Compared with the wild type, the rres 1 mutants showed reduced hypocotyl elongation after $\mathrm{NaCl}$ treatment, and the phenotype was recovered in the complementation lines (Fig. 2a-d). Similar to the seedlings grown under normal light conditions, the rres1 mutants grown under 


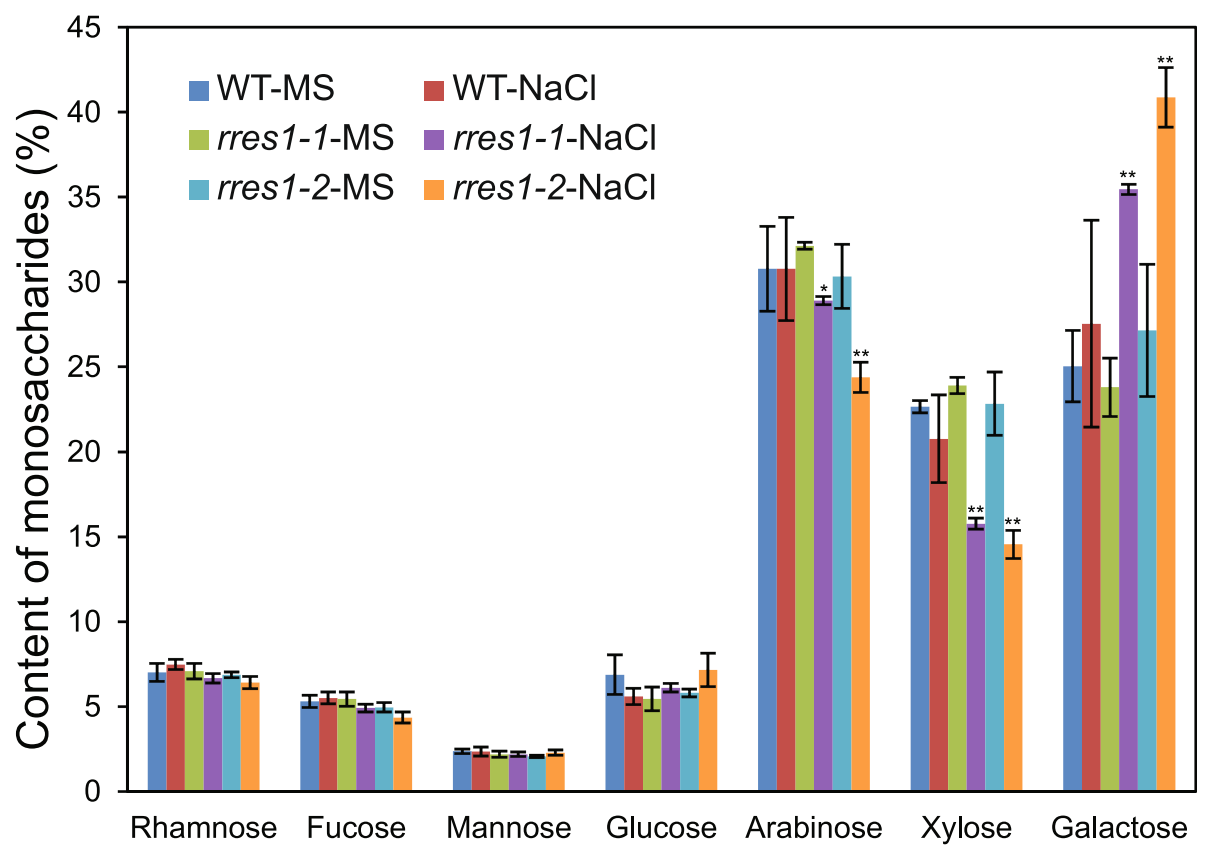

Fig. 5 Monosaccharide contents in the roots of rres 1 mutants under salt stress. The seedlings of the wild type, rres $1-1$, and $r$ res $1-2$ were treated with or without $\mathrm{NaCl}$, and cell wall components were extracted for the analysis of each monosaccharide content. Values are means \pm SD $(n=3)$. Asterisks indicate statistically significant differences $\left({ }^{*} p<0.05,{ }^{* *} p<0.01\right.$ by Student's $t$ test)

continuous dark conditions also showed enhanced root growth inhibition under high salinity (Fig. 2e and f). These results suggested that RRES1 is required for salt tolerance in whole seedlings. We also tested the phenotypes of the rres1 mutants and complementation lines grown on $\mathrm{NaNO}_{3}, \mathrm{KCl}$, and $\mathrm{KNO}_{3}$ media under dark conditions. The hypocotyl and root elongation of the rres 1 mutants were both inhibited by these salts, while the complementation lines showed similar phenotypes as the wild type (Fig. 2). In addition, the rres1 mutants also exhibited slightly impaired hypocotyl elongation under osmotic stress (Fig. 2).

\section{The rres 1 mutation results in short meristem zone and reduced auxin accumulation under salt stress}

As rres1 mutant exhibited reduced root elongation under salt stress, we took a close view of root cells under a microscope. Under normal conditions, both the rres11 and rres1-2 mutants displayed normal root morphology, but developed more and longer root hairs (Fig. 3a). Under salt stress, however, root elongation was severely inhibited in the rres1 mutants (Fig. 3a). Moreover, we noted that meristem zone length in the rres1 mutants was slightly reduced under normal conditions, but it was strongly reduced under salt stress (Fig. 3b and c). Microscopic pictures also showed that meristem zones were more thickened in the rres1 mutants than that in the wild type after being exposed to salt stress (Fig. $3 \mathrm{~b}$ and $\mathrm{c}$ ). These results suggested that RRES1 is required for the maintenance of meristem activity under salt stress.

Auxin plays critical roles in plant root growth by regulating cell division, expansion, and differentiation (Malamy \& Ryan, 2001). To understand whether root growth arrest and reduced meristem zone length in the rres 1 mutant under salt stress is caused by the disruption of auxin signaling pathway, auxinresponsive DR5:GFP marker was explored to monitor the accumulation and distribution of auxin (Friml et al., 2003). We crossed DR5:GFP transgenic plant with the rres1-1 and rres1-2 mutants and detected auxin accumulation in the wild type and rres $1 \mathrm{mu}-$ tants. Without salt treatment, green fluorescence intensity in primary root tips was similar between the wild type and rres 1 mutants (Fig. 3d and e). Under salt stress, green fluorescence intensity was reduced in the wild type, which is consistent with a previous report (Liu et al., 2015). In the rres1 mutants, however, the salt stress-triggered inhibition of auxin accumulation was enhanced compared with the wild type (Fig. 3d and e), suggesting that RRES1 is required for the maintenance of auxin accumulation under salt stress. To understand the molecular mechanism underlying the regulation of auxin accumulation by RRES1, we searched for potential RRES1-interacting proteins based on the protein-protein interactome Database. We found that WAT1 (Walls Are Thin1), which functions as an auxin transporter (Ranocha 


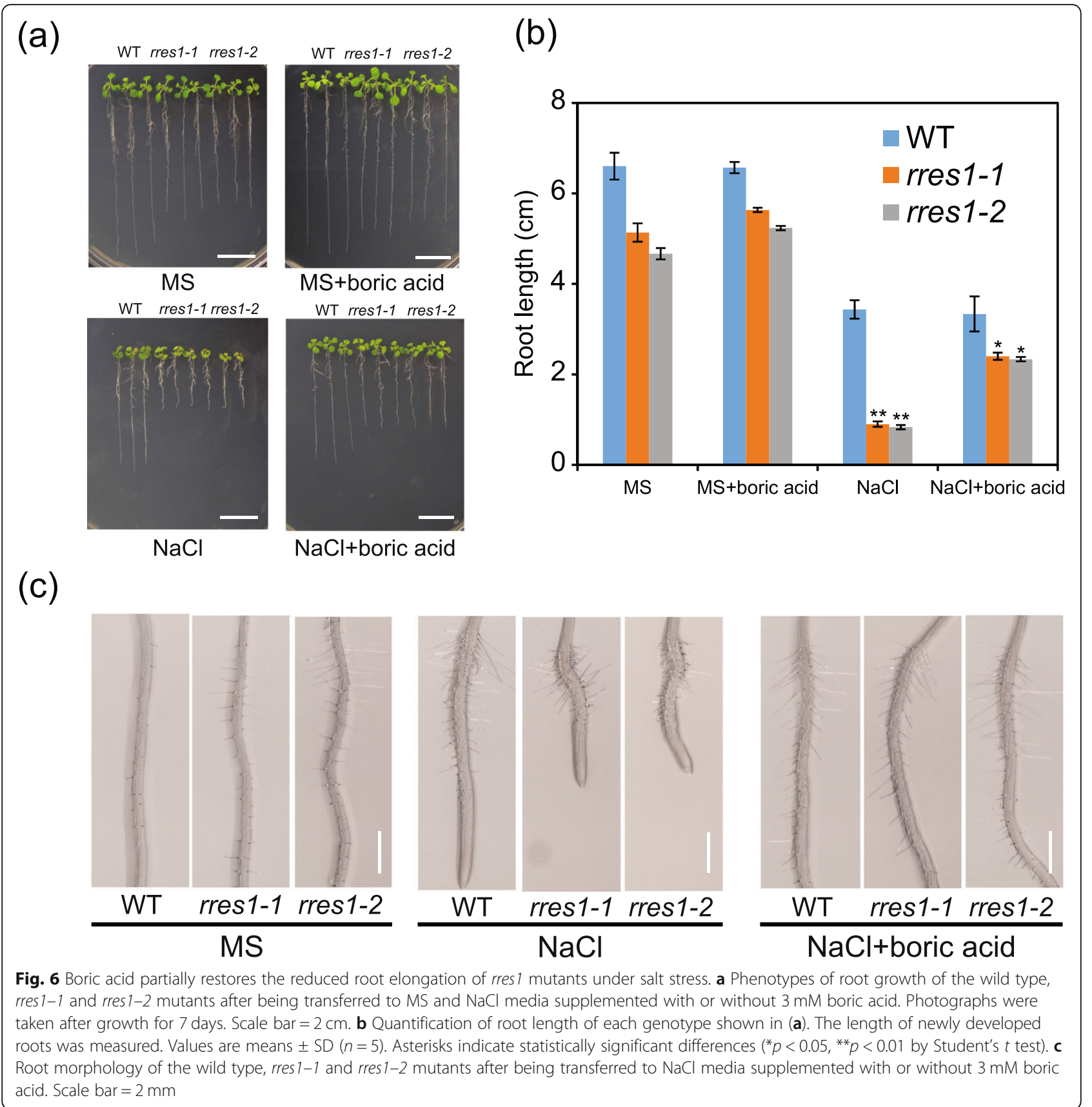

et al., 2013), is annotated as an interacting protein of RRES1. To verify this interaction, we performed splitLUC assay in $N$. benthamiana. Unfortunately, no interaction was observed between RRES1 and WAT1, but we found that WAT1 could form a homodimer (Fig. S6).

The rres1 mutants exhibit an increased ROS accumulation in roots under salt stress

It has been shown that salt stress increases the production of ROS in plant cells, and ROS are involved in the regulation of root elongation (Hazman et al., 2015). Hence, we employed $\mathrm{H}_{2}$ DCFDA and DAB to detect ROS accumulation in primary root, respectively. ROS levels were similar between the wild type and rres1 mutants under normal conditions, and salt stress triggered ROS accumulation in both the wild type and rres1 mutants (Fig. 4a-d). However, both assays supported that the rres 1 mutants accumulated more ROS than the wild type after being exposed to salt stress (Fig. 4a-d), suggesting that RRES1 is a negative regulator of ROS accumulation in response to salt stress. 
(a)

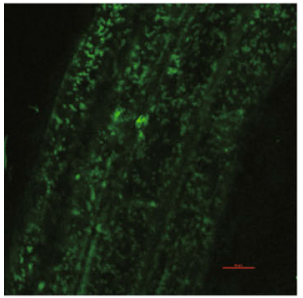

RRES1-GFP

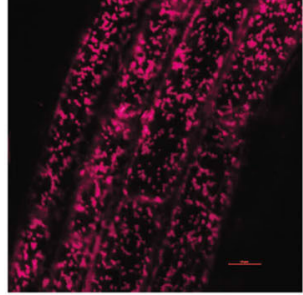

TMRM

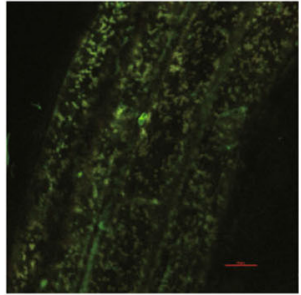

Merged

(b)

๖े

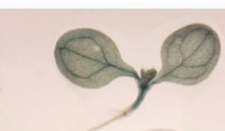

(ii)
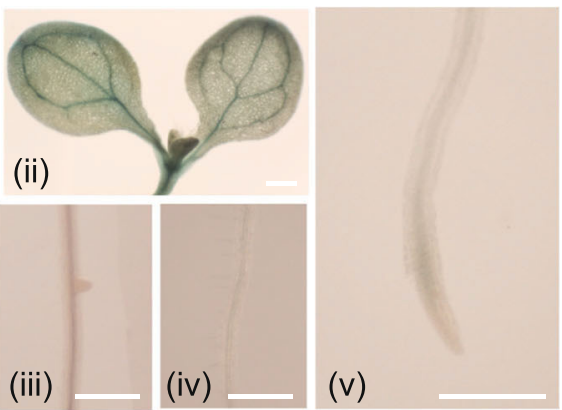

(i)
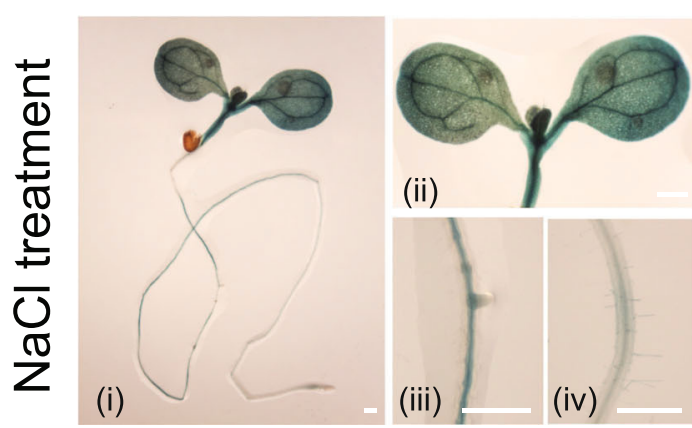

(iii)

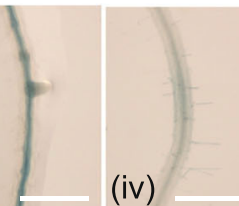

(v)

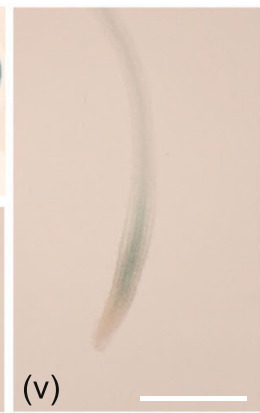

(c)

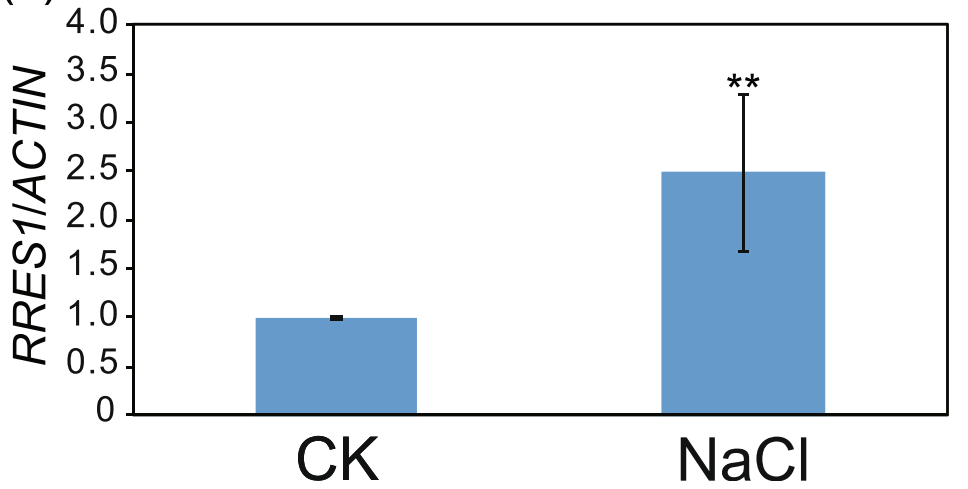

Fig. 7 Subcellular localization and tissue-specific expression pattern of RRES1. a Subcellular localization of the RRES1 fused with GFP tag was examined by confocal microscopy. Tetramethylrhodamine methyl ester (TMRM) was applied as a fluorescence dye of mitochondria. $\mathbf{b}$ ProRRES1:GUS transgenic plants were generated to analyze the expression of RRES1 in whole seedling (i), cotyledon (ii), mature root (iii), lateral root (iv), and root tip (v) before (upper panel) and after (bottom panel) salt treatment. Scale bar $=2 \mathrm{~mm}$. c qRT-PCR analysis of the transcript level of RRES1 gene before and after $\mathrm{NaCl}(150 \mathrm{mM})$ treatment for $6 \mathrm{~h}$. ACTIN8 was used as an internal control. Values are means \pm SD $(n=3)$. Asterisks indicate a statistically significant difference $\left({ }^{* *} p<0.01\right.$ by Student's $t$ test) 


\section{Arabinose and xylose contents are decreased in the rres 1 mutant under salt stress}

Exposure of plants to salt stress can rapidly induce the compositional and structural changes of cell wall, and the ability to maintain cell wall integrity is critical for plants to tolerate salt stress. As rres 1 mutants exhibited root and hypocotyl elongation defects under salt stress, we speculated that cell wall components are probably affected in the rres 1 mutant. To test this hypothesis, we measured the contents of monosaccharides, including rhamnose, fucose, arabinose, xylose, mannose, glucose, and galactose in the cell wall of the rres1 mutants. The roots of the wild type and rres 1 mutants before and after salt treatment were collected and cell wall components were extracted to determine the relative amount of each monosaccharide. The contents of rhamnose, fucose, mannose, and glucose were not altered in the rres 1 mutant with or without salt treatment. However, arabinose and xylose contents were significantly reduced in the rres $1 \mathrm{mu}-$ tants after salt treatment, despite a similar amount of these two monosaccharides was observed between the wild type and rres1 mutants under normal conditions (Fig. 5). Moreover, compared with the wild type, the relative amount of galactose in the rres 1 mutants was slightly increased under normal conditions and largely increased under salt stress (Fig. 5). Together, these results indicated that RRES1 is involved in controlling the abundance of arabinose, xylose, and galactose, and thus facilitates the maintenance of cell wall integrity under salt stress.

\section{Boric acid partially restores the short primary roots of the rres 1 mutants under salt stress}

Boric acid is essential for the cross-linking of pectic polysaccharide rhamnogalacturonan-II (RG-II), which in turn promotes cell wall strength (Match, 1997). Studies have shown that application of boric acid can rescue the deficient phenotypes of the mutants that are disrupted in cell wall biosynthesis (O'Neill et al., 2001). To support that the reduced root elongation in the rres 1 mutants under salt stress is caused by cell wall defects, the effect of the exogenous boric acid on the root elongation of the rres 1 mutants was analyzed. On MS medium, the root growth of the rres1 mutants was slightly increased when boric acid was applied. Under salt stress, the exogenous boric acid had no obvious effect on the root growth of the wild type, but could largely restore the root elongation of the rres 1 mutants (Fig. 6). Assessment of different concentrations of boric acid showed that $3 \mathrm{mM}$ is the optimized concentration to promote the root elongation of the rres 1 mutants under salt stress. The boric acid with a concentration more than $5 \mathrm{mM}$ caused a toxic effect on the root growth of both the wild type and rres 1 mutants (Fig. S7). Together, these results corroborated that the salt-hypersensitive phenotype of the rres 1 mutant is largely attributed to cell wall deficiency.

\section{RRES1 is localized in the mitochondrion and its gene expression is induced under salt stress}

Based on the TAIR database, RRES1 is predicted to be localized in mitochondrion. To experimentally determine the subcellular localization of RRES1, we observed fluorescence signal in RRES1-GFP transgenic plants by using confocal microscopy. Green fluorescence was found in a large number of discrete puncta (Fig. 7a), which are reminiscent of the structure of mitochondria. We then explored tetramethylrhodamine methyl ester (TMRM), a fluorescent dye that is often used to label mitochondria in living cell. As expected, GFP fluorescence was overlapped with TMRM signal, indicating that RRES1 is localized in the mitochondrion (Fig. 7a).

To determine the tissue-specific expression pattern of the RRES1 gene, we generated transgenic plants expressing ProRRES1:GUS. Under normal conditions, the GUS was mainly expressed in leaves and weakly in root tip. After salt treatment for $12 \mathrm{~h}$, however, the GUS staining signal was obviously increased in leaves, lateral root, root hair, and root tip (Fig. 7b), suggesting that RRES1 promoter is responsive to salt stress. Consistently, qRT-PCR analysis also showed that the expression of RRES1 gene was significantly up-regulated after salt treatment (Fig. 7c).

\section{Discussion}

After being subjected to salt stress, plants utilize a multitude of mechanisms to maintain root elongation, which could be important for seedling establishment and ensuring adequate supply of water and nutrients for plant growth (Petricka et al., 2012). In addition, maintenance of root growth facilitates plants to escape from high concentration of salts via a process of halotropism response (Galvan-Ampudia \& Testerink, 2011). Therefore, tight regulation of root elongation would be beneficial for plant growth and survival under salt stress. In this study, we reveal a novel mitochondrial protein that participates in the regulation of primary root elongation under salt stress via the modulation of cell wall integrity, ROS homeostasis, and auxin accumulation.

Plant cell wall is a polymer matrix that is comprised of cellulose, hemicellulose, pectin, and structural proteins (McNeil et al., 1984). Plant cell wall not only determines plant growth and development, but is also required for response and adaption to environmental stresses. High salinity can cause a significant change of cell wall components and structure, which in turn affects cell division 
and expansion (Wolf et al., 2012; Draeger et al., 2015). Accumulating evidence indicates that the plants that are not capable to synthesize cell wall components often lose ability to tolerate salt stress. Arabinose and xylose are important constitutes of pectin polymer side chain (Burget \& Reiter, 1999; Burget et al., 2003; Harholt et al., 2010), and it has been demonstrated that disruption of UDP-Xyl and UDP-Ara biosynthesis results in severe root growth inhibition under salt stress (Zhao et al, 2019). Here, we found that the rres 1 mutant showed reduced arabinose and xylose contents under salt stress, suggesting that the reduced root elongation of the rres 1 mutant is likely caused by cell wall defects. This result is consistent with the putative function of RRES1 as a nucleotide-diphospho-sugar transferase, although more experimental evidence is required to demonstrate the glycosyltransferase activity of RRES1. Boron plays a structural role in plant cell wall and boron deficiency causes decreased cross-linking of RG-II, which subsequently leads to plant growth inhibition ( $\mathrm{Hu} \&$ Brown, 1994; O'Neill et al., 2004). In this study, we found that exogenous boric acid application promoted the root elongation of the rres 1 mutant under salt stress in a dose-dependent manner, corroborating that RRES1 participates in the regulation of cell wall integrity under salt stress. However, it is well-known that cell wall polymers are synthesized in the Golgi, so how the mitochondrionlocalized RRES1 protein engages in cell wall biosynthesis needs to be further addressed.

ROS are important signals that are required for the regulation of plant development and responses to a variety of environmental stresses. Despite the versatile roles, the exact functional mode of ROS in response to abiotic stress is still largely elusive. Salt stress rapidly increases the accumulation of ROS in both shoots and roots and excessive production of ROS causes oxidative damage on plants (Suzuki et al., 2012). In Arabidopsis, ABA-promoted ROS are important retrograde signals in regulating root meristem activity and root growth by controlling auxin signaling pathway (Yang et al., 2014). Furthermore, mutation of catalase-encoding gene CAT2 results in severe root growth inhibition under $\mathrm{H}_{2} \mathrm{O}_{2}$ treatment, indicating the important role of catalase in maintaining root meristem activity under oxidative stress (Tsukagoshi, 2012). In rice, it was also reported that excessive accumulation of $\mathrm{H}_{2} \mathrm{O}_{2}$ caused by $\mathrm{NaCl}$ inhibits root growth (Lin \& Kao, 2001). In this study, we found that the rres1 mutant generated more $\mathrm{H}_{2} \mathrm{O}_{2}$ than that of the wild type after salt treatment, which could be one of the factors that cause root elongation inhibition under salt stress. In plants, ROS are mainly produced in the apoplast, chloroplast, mitochondrion, and peroxisome. Given the mitochondrion localization of RRES1 protein, whether RRES1 mediates the production of ROS in the mitochondrion needs to be further studied.
Auxin plays critical roles in plant root growth by regulating cell division, expansion, and differentiation (Malamy \& Ryan, 2001). Salt stress affects auxin accumulation and distribution in root tip, and thus causes reduced root growth (Wang et al., 2009; Liu et al., 2015). IAR4 encodes a putative mitochondrial pyruvate dehydrogenase $\mathrm{E} 1 \alpha$-subunit that functions as a regulator of auxin homeostasis. Mutation of IAR4 does not obviously affect growth under normal conditions, but dramatically decreases root elongation under salt stress, and this phenotype is proposed to be caused by increased ROS production and reduced auxin accumulation (Fu et al., 2019). Consistent with this observation, we found that the salt-triggered decrease of DR5:GFP expression was enhanced in the rres1 mutant, suggesting that RRES1 is required for the regulation of auxin homeostasis under salt stress. ROS are proposed as important mediators between salt stress and auxin (Fu et al., 2019), so whether RRES1 directly regulates auxin pathway or through ROS-mediated pathway remains to be determined. The well-known function of auxin is to regulate root meristem activity (Liu et al., 2015). In line with the reduced auxin accumulation, the rres 1 mutants exhibited a reduced meristem length under salt stress. Together, these results suggest that the reduced meristem activity in the rres 1 mutant could be responsible for the reduced root elongation under salt stress.

It has been reported that salt-hypersensitive mutants, including mur4, pp2a-c5-1, sos5, and sos6, are not only sensitive to $\mathrm{Na}^{+}$but also exhibits increased sensitivity to $\mathrm{K}^{+}$ (Shi et al., 2003; Zhu et al., 2010; Hu et al., 2017; Zhao et al., 2019). Similarly, the rres1 mutant showed reduced root growth under both $\mathrm{NaCl}$ and $\mathrm{KCl}$, and within a similar ion concentration, the $\mathrm{K}^{+}$has a more severe effect than the $\mathrm{Na}^{+}$on the root growth inhibition of the rres1 mutant. In fact, early studies have uncovered that in some plants the impairment caused by $\mathrm{K}^{+}$is more serious than that of $\mathrm{Na}^{+}$(Eshel, 1985; Cramer et al., 1990). In Chenopodium album, due to the different patterns of antioxidant response and ion regulation, plant growth is more affected by $\mathrm{KCl}$ than that by $\mathrm{NaCl}$ (Yao et al., 2010). In some halophytes, plasma membrane ATPase activity is reduced to a greater extent by $\mathrm{KCl}$ than $\mathrm{NaCl}$, and this may account for the inhibition of photosynthesis and plant growth caused by $\mathrm{KCl}$ (Zhao et al., 1995). Another study elucidated that the severe impairment of plant growth caused by a high concentration of $\mathrm{K}^{+}$is due to the significant decrease of $\mathrm{H}^{+}$-pumping activity at the plasma membrane (Liu \& Wu, 1999). In future, the mechanism underlying the severe toxicity of high $\mathrm{K}^{+}$on the rres 1 mutant needs to be further investigated.

\section{Materials and methods}

Plant materials and growth conditions

All Arabidopsis materials used in this study were in Columbia (Col-0) background. Two T-DNA insertion 
mutants SALK_027606 and SALK_004322 were obtained from the Arabidopsis Stock Center (ABRC). DR5:GFP plant was a gift from Dr. Lei Ge (Shandong Agricultural University). Arabidopsis seeds were surface sterilized for $5 \mathrm{~min}$ with $1 \%$ Sodium hypochlorite, and washed three times with sterile water. The sterilized seeds were sown on half Murashige and Skoog (MS) medium containing $1 \%$ sucrose and $0.8 \%$ agar and vernalized for $3 \mathrm{~d}$ at $4{ }^{\circ} \mathrm{C}$ before they were placed in a chamber at $23^{\circ} \mathrm{C}$ with long-day light cycle $(16 \mathrm{~h}$ light $/ 8 \mathrm{~h}$ dark). For stress treatment, five-day-old seedlings grown on MS medium were transferred onto plates supplemented with different concentrations of $\mathrm{NaCl}, \mathrm{KCl}, \mathrm{KNO}_{3}, \mathrm{NaNO}_{3}$, or mannitol. After growth for around 5 days, the seedlings were photographed by a digital camera (PowerShot SX20IS, Canon, Japan). For the quantification of root length, only the newly developed root was measured. Primers used for genotyping are listed in Table S1.

\section{Generation of transgenic plants}

To generate RRES1 complementation lines, the genomic sequence of RRES1 containing $2 \mathrm{~kb}$ promoter sequence was amplified by high-fidelity DNA polymerase (PrimeSTAR HS DNA Polymerase, Clontech). The PCR product was first introduced into pDONR207 vector (Invitrogen) by $\mathrm{BP}$ reaction, and then was cloned into destination vector pMDC107 vector via LR reaction. After verification of the construct by using traditional Sanger sequencing, the construct was transformed to rres1 mutants via an Agrobacterium tumefaciens-mediated floral-dip method.

\section{Split firefly luciferase (LUC) complementation assay}

The full-length coding sequences of RRES1 and WAT1 were amplified by PCR using primers listed in Table S1. The PCR products were first cloned into pDONR207 vector using BP clonase II (Invitrogen) and then recombined into nLUC or cLUC vectors via $L R$ reactions. Split-LUC complementation assay was performed in tobacco (Nicotiana benthamiana) leaves (Christian et al., 2011). After $48 \mathrm{~h}$, luciferin was sprayed on leaves, and fluorescence was detected using a charge-coupled device (CCD) camera (Prince-ton Instruments, Trenton, NJ, USA). Images and quantification of LUC activity were processed by using WinView software.

\section{Drought stress assay}

Water loss assay was performed by using the aerial part of four-week-old plants grown under normal conditions. For each replicate, three plants were placed on a piece of weighing paper under light conditions, and the weight of the plants was measured every $10 \mathrm{~min}$. The relative change of fresh weight at each time point was calculated to assess water loss rate. Three replicates were performed for each genotype. To perform drought stress assay in soil, seven-day-old seedlings were transferred to soil and grown for 2 weeks under normal conditions, and then plants were subjected to drought treatment by stopping watering for the next 2 weeks.

\section{Measurement of ROS in plants}

Eight-day-old seedlings of the wild type, rres1-1, and rres1-2 were incubated in liquid MS with or without $150 \mathrm{mM} \mathrm{NaCl}$ for $12 \mathrm{~h}$ before the seedlings were stained. For 3', 3'-diaminobenzidine (DAB) staining, the seedlings were immersed in $1.0 \mathrm{mg} / \mathrm{mL}$ DAB (Sigma-Aldrich) dissolved in $50 \mathrm{mM}$ Tris- $\mathrm{HCl}$ (pH 5.0) for $10 \mathrm{~h}$ and then washed three times with water. The roots were then photographed using a Carl Zeiss HBO100 microscope. For chloromethyl derivative of 2',7'-dichlorodihydrofluorescin diacetate $\left(\mathrm{CM}-\mathrm{H}_{2} \mathrm{DCFDA}\right)$ staining, seedlings were incubated in a buffer containing $10 \mu \mathrm{M} \mathrm{CM}$ $\mathrm{H}_{2}$ DCFDA (Sigma-Aldrich) at $37^{\circ} \mathrm{C}$ in darkness for 30 min and then washed with distilled $\mathrm{H}_{2} \mathrm{O}$ to remove excess $\mathrm{CM}-\mathrm{H}_{2} \mathrm{DCFDA}$. The roots were then photographed using a Carl Zeiss HBO100 microscope. ROS levels were quantified based on the intensity of fluorescence by using ImageJ software (NIH, http://rsb.info.nih.gov/ij/).

\section{Measurement of root meristems}

Seeds were germinated on half-strength MS medium as described above and five-day-old seedlings were transferred to MS media supplemented with or without $100 \mathrm{mM} \mathrm{NaCl}$. After growth for 5 days, roots were excised and immersed immediately in clean solution (5 g chloral hydrate, $1.5 \mathrm{~mL}$ water, and $1 \mathrm{~mL}$ glycerol) and then were photographed by using an Olympus BH2 microscope. Root meristem zone was defined according to published approach (Dello et al., 2007), and root meristem length was measured as described previously (Yuan et al., 2013).

\section{Detection of DR5:GFP fluorescence}

Transgenic plants carrying ProDR5:GFP were crossed with rres1-1 and rres 1-2 mutants, and $\mathrm{F}_{2}$ seedlings were screened on MS media containing $50 \mathrm{mg} / \mathrm{L}$ hygromycin. Meanwhile, hygromycin-resistant seedlings were genotyped for the rres1 mutations using specific primers (Table S1). The hygromycin-resistant and homozygous $F_{3}$ seeds were sown on MS for 5 days and then were transferred to MS media supplemented with or without $100 \mathrm{mM} \mathrm{NaCl}$, and grown for an additional $8 \mathrm{~h}$. Seedlings were photographed by a Carl Zeiss HBO100 microscope. The intensity of fluorescence was quantified using ImageJ software. 


\section{Quantification of monosaccharides in cell wall}

Cell walls were extracted based on the protocol described previously (Mertz et al., 2012). Briefly, seeds were grown on MS medium for 5 days. For salt treatment, half of fiveday-old seedlings were transferred onto plates supplemented with $100 \mathrm{mM} \mathrm{NaCl}$. Three biological replicates were performed for each sample. After 15 days, roots were collected and rapidly frozen into liquid nitrogen. The samples were grounded and suspended in $50 \mathrm{mM}$ Tris [HCl] (pH 7.2) mixed with 1\% SDS. Suspensions were vortexed and centrifuged at $2500 \mathrm{~g}$ for $5 \mathrm{~min}$, and pellets were resuspended in the same buffer and heated at $65^{\circ} \mathrm{C}$ for 20 min. After that, the pellets were washed with $50^{\circ} \mathrm{C}$ water for three times, with $50 \%$ ethanol for three times, and with water for three times. The isolated cell walls were freeze dried for further analysis.

$2.0 \mathrm{mg}$ of each cell wall material (totally 18 samples) was carboxyl-reduced with $\mathrm{NaBD}_{4}$ and acetylated in 1-MethylImidazole as described previously (Gibeaut \& Carpita, 1991). Samples were added with $0.6 \mathrm{ml}$ solution containing $0.5 \mathrm{ml}$ of fresh $20 \mathrm{mg} / \mathrm{ml} \mathrm{NaBH}_{4}$ in DMSO plus $0.1 \mathrm{ml}$ of $1 \mathrm{M} \mathrm{NH} \mathrm{NH}_{4} \mathrm{OH}$. Then the samples were incubated at $45^{\circ} \mathrm{C}$ in water bath for $90 \mathrm{~min}$ with vortex every $30 \mathrm{~min}$. The samples were chilled in a freezer for $15 \mathrm{~min}$ and neutralized with $100 \mu$ glacial acetic acid (letting it run slowly down along the side of tubes), and then mixed thoroughly until fizzing stopped. Next $100 \mu \mathrm{L}$ 1-methylimidazole $\left(4{ }^{\circ} \mathrm{C}\right)$ and $0.75 \mathrm{ml}$ anhydrous acetic anhydribe were added. The tubes were capped tightly and mixed thoroughly before they were incubated at $45{ }^{\circ} \mathrm{C}$ in water bath for 30 min. Then add $1.5 \mathrm{ml} \mathrm{H}_{2} \mathrm{O}$ and fill remaining volume with dichloromethane $\left(\mathrm{CH}_{2} \mathrm{Cl}_{2}\right)$, shake vigorously for $30 \mathrm{~s}$ and spin at $2500 \mathrm{rpm}$ for $3 \mathrm{~min}$. Pour off the suspension and refill with $\mathrm{H}_{2} \mathrm{O}$. The samples were washed with water for five times and then the $\mathrm{CH}_{2} \mathrm{Cl}_{2}$ was evaporated at $45^{\circ} \mathrm{C}$. The last step is to redissolve the samples in $0.5 \mathrm{ml} \mathrm{CH}_{2} \mathrm{Cl}_{2}$ for GC-MS analysis.

\section{GUS staining assay}

RRES1 promoter (approximately $2 \mathrm{~kb}$ ) was amplified by PCR and then the PCR product was cloned into binary vector pMDC162 (with a GUS coding region). The binary construct was transformed into wild-type (Col-0) plants via Agrobacterium-mediated transformation as described above. Eight-day-old hygromycin-resistant $\mathrm{T}_{2}$ transgenic seedlings grown vertically on MS were transferred to the media supplemented with or without $100 \mathrm{mM} \mathrm{NaCl}$ and the seedlings were grown for an additional $8 \mathrm{~h}$. For GUS staining, seedlings were incubated in X-Gluc solution $(0.5 \mathrm{mg} / \mathrm{ML} \mathrm{X}$ Gluc, $0.1 \%$ sodium phosphate buffer ( $\mathrm{pH} 7.0), 0.5 \%$ Triton $\mathrm{X}-100,5 \mathrm{mM} \mathrm{K}_{3}\left[\mathrm{Fe}(\mathrm{CN})_{6}\right], 5 \mathrm{mM} \mathrm{K}_{4}\left[\mathrm{Fe}(\mathrm{CN})_{6}\right]$, and $0.02 \%$ NaN3) at $37^{\circ} \mathrm{C}$ overnight in the dark. Then the seedlings were incubated in $70 \%$ ethanol for $12 \mathrm{~h}$ to remove chlorophyll and photographed using a Leica EZ4 HD.

\section{Subcellular localization}

Based on the TAIR (www.arabidopsis.org) database, RRES1 is predicted to be localized in mitochondrion. We performed mitochondrion staining of 10-days-old RRES1-GFP transgenic seedlings by using TMRM solution. Images were obtained using a Carl Zeiss LSM510 META laser scanning microscope.

\section{Supplementary Information}

The online version contains supplementary material available at https://doi. org/10.1007/s44154-022-00036-3.

\begin{abstract}
Additional file 1: Table S1. Primers used in this study.
Additional file 2: Fig. S1. Identification of 19-1 mutant that is hypersensitive to salt stress. (a) Root growth of seedlings grown on MS media supplemented with or without $\mathrm{NaCl}(120 \mathrm{mM})$ for 7 days. (b) Quantification of root length in the wild type and mutant under salt stress. The length of newly developed roots was measured. Values indicate means $\pm \mathrm{SD}(n=5)$. Asterisks indicate statistically significant differences $\left({ }^{*} p<0.05,{ }^{* *} p<0.01\right.$ by Student's $t$ test). (c) Identification of mutations in the 19-1 mutant by bulk segregant analysis.
\end{abstract}

Additional file 3: Fig. S2. Developmental phenotypes of rres 1 mutants (a) Phenotype of plants grown on soil for 4 weeks. Bar $=3 \mathrm{~cm}$. (b) Plant height of each plant after growth for 6 weeks. Bar $=2 \mathrm{~cm}$. (c) Flower phenotype of each genotype. (d) Pictures showing the seeds of each genotype. (e) Quantification of the length and width of seeds. Values indicate means \pm SD $(n=20)$. Asterisk indicates a statistically significant difference ( ${ }^{*} p<0.05$ by Student's $t$ test). (f) Silique phenotype of each genotype. (g) Quantification of the length of the siliques shown in (f). Values indicate means \pm SD $(n=5)$. Asterisk indicates statistically significant differences ( ${ }^{*} p<0.05$ by Student's $t$ test).

Additional file 4: Fig. S3. Complementation of rres 1 mutants. (a) Phenotypes of the wild type, rres 1-1, rres 1-2, and complementation lines after being transferred to MS media supplemented with or without 100 $\mathrm{mM} \mathrm{NaCl}$ for 7 days. (b) Quantification of root length of the wild type, rres 1-1, rres 1-2, and complementation lines after being transferred to MS media supplemented with or without $100 \mathrm{mM} \mathrm{NaCl}$ for 7 days. The length of newly developed roots was measured. Values are means \pm SD $(n=5)$. Asterisks indicate statistically significant differences $\left({ }^{* *} p<0.01\right.$ by Student's $t$ test).

Additional file 5: Fig. S4. rres 1 mutants were not sensitive to drought stress. (a) Water loss assay of the wild type, rres 1-1, and rres 1-2 mutants. Nine seedlings that grown on MS media for 10 days we detached from soil and weighed every 10 min under normal conditions. (b) Drought tolerance assay of the wild type, rres $1-1$ and rres $1-2$ mutants grown on soil.

Additional file 6: Fig. S5. Seed germination and cotyledon greening rates of rres 1 mutants under stress conditions. (a) Seeds germination rate of the wild type, rres1-1, and rres1-2 mutants grown on MS or MS media supplemented with $\mathrm{NaCl}(120 \mathrm{mM}), \mathrm{ABA}(3 \mathrm{mM})$, and mannitol $(0.5 \mathrm{M})$. (b) Cotyledon greening rate of each genotype grown on MS or MS media supplemented with $\mathrm{NaCl}(120 \mathrm{mM}), \mathrm{ABA}(3 \mathrm{mM})$, and mannitol (0.5 M).

Additional file 7: Fig. S6. RRES1 does not interact with auxin transporter WAT1. Split luciferase complementation assay was explored to test the interaction of RRES1 with WAT1 and also the formation of RRES1 and WAT1 homodimers. The constructs expressing the indicated genes were cotransformed into $N$. benthamiana leaves through Agrobacterium infiltration. Luciferase activity was determined at $48 \mathrm{~h}$ after infiltration. nLUC represents the N-terminal fragment of firefly luciferase; CLUC represents the C-terminal fragment of firefly luciferase.

Additional file 8: Fig. S7. Boric acid rescues the reduced root elongation of rres 1 mutants under salt stress in a concentration-dependent manner. (a) Root growth phenotype of the wild type, rres 1-1, and rres 1-2 after being transferred to $\mathrm{NaCl}$ media supplemented with different concentrations of boric acid (0.5 mM, 1 mM, 3 mM, 5 mM, and $10 \mathrm{mM})$ for 7 days. (b) 
Quantification of the root length of the wild type, rres 1-1, and rres 1-2 shown in (a). Values are means $\pm \mathrm{SD}(n=5)$. Asterisks indicate statistically significant differences $\left({ }^{*} p<0.05,{ }^{* *} p<0.01\right.$ by Student's $t$ test).

\section{Authors' contributions}

C.Z. conceived and supervised this study. Z.Y. and C.Z. designed the experiments; Z.Y., Y.R., and J.L. performed all the experiments; Z.Y. wrote the manuscript with constructive input from all authors; and J.-K.Z. and C.Z. revised the manuscript. All authors read and approved the final manuscript.

\section{Funding}

This work was supported by Shanghai Pujiang Program, Grant 20PJ1414800 (to C.Z.), National Natural Science Foundation of China, Grant 32070295 (to C.Z.), Strategic Priority Research Program of the Chinese Academy of Sciences, Grant XDB27040101 (to J-K.Z.), and Shanghai Agriculture Applied Technology Development Program, Grant G2020-01-01 (to C.Z.).

\section{Availability of data and materials}

All data generated or analysed during this study are included in this published article and its supplementary information files.

\section{Declarations}

\section{Ethics approval and consent to participate}

Not applicable.

\section{Consent for publication}

Not applicable.

\section{Competing interests}

J.-K.Z. is a member of the editorial board but was not involved in the journal's review, or any decisions, related to this submission.

Received: 1 December 2021 Accepted: 11 January 2022

Published online: 08 February 2022

\section{References}

Burget EG, Reiter WD (1999) The mur4 mutant of Arabidopsis is partially defective in the de novo synthesis of uridine diphospho L-arabinose. Plant Physiol 121(2):383-389. https://doi.org/10.1104/pp.121.2.383

Burget EG, Verma R, Mølhøj M, Reiter WD (2003) The biosynthesis of L-arabinose in plants: molecular cloning and characterization of a Golgi-localized UDP-Dxylose 4-epimerase encoded by the MUR4 gene of Arabidopsis. Plant Cell 15(2):523-531. https://doi.org/10.1105/tpc.008425

Christian G, David K, Domenica H, Rolf B, Jörg K, Ralf RM, Robert H (2011) Quantitative analysis of dynamic protein-protein interactions in planta by a floated-leaf luciferase complementation imaging ( $\mathrm{FLuCl}$ ) assay using binary Gateway vectors. Plant J 67(3):542-553. https://doi.org/10.1111/j.1365-313X.2 011.04607.x.

Cramer GR, Epstein E, André L (1990) Effects of sodium, potassium and calcium on salt-stressed barley. I. Growth analysis. Physiol Plant 80(1):83-88. https:// doi.org/10.1111/j.1399-3054.1990.tb04378.x

Dello LR, Linhares FS, Scacchi E, Casamitjana-Martinez E, Heidstra R, Costantino P, Sabatini S (2007) Cytokinins determine Arabidopsis root-meristem size by controlling cell differentiation. Curr Biol 17(8):678-682. https://doi.org/10.101 6/j.cub.2007.02.047

Deslauriers SD, Larsen PB (2010) FERONIA is a key modulator of brassinosteroid and ethylene responsiveness in Arabidopsis hypocotyls. Mol Plant 3(3):626640. https://doi.org/10.1093/mp/ssq015

Draeger C, Ndinyanka Fabrice T, Gineau E, Mouille G, Kuhn BM, Moller I, Abdou MT, Frey B, Pauly M, Bacic A, Ringli C (2015) Arabidopsis leucine-rich repeat extensin (LRX) proteins modify cell wall composition and influence plant growth. BMC Plant Biol 15:155. https://doi.org/10.1186/s12870-015-0548-8

Endler A, Kesten C, Schneider R, Zhang Y, Ivakov A, Froehlich A, Funke N, Persson $S$ (2015) A mechanism for sustained cellulose synthesis during salt stress. Cell 162(6):1353-1364. https://doi.org/10.1016/j.cell.2015.08.028

Eshel A (1985) Response of Suaeda aegyptiaca to $\mathrm{KCl}, \mathrm{NaCl}$ and $\mathrm{Na}_{2} \mathrm{SO}_{4}$ treatments. Physiol Plant 64(3):308-315. https://doi.org/10.1111/j.1399-3054.1 985.tb03345.x
Feng W, Kita D, Peaucelle A, Cartwright HN, Doan V, Duan Q, Liu MC, Maman J, Steinhorst L, Schmitz-Thom I, Yvon R, Kudla J, Wu HM, Cheung AY, Dinneny JR (2018) The FERONIA receptor kinase maintains Cell-Wall integrity during salt stress through Ca2+ signaling. Curr Biol 28(5):666-675.e5. https://doi. org/10.1016/j.cub.2018.01.023

Friml J, Vieten A, Sauer M, Weijers D, Schwarz H, Hamann T, Offringa R, Jürgens G (2003) Efflux-dependent auxin gradients establish the apical-basal axis of Arabidopsis. Nature 426(6963):147-153. https://doi.org/10.1038/nature02085

Fu Y, Yang Y, Chen S, Ning N, Hu H (2019) Arabidopsis IAR4 modulates primary root growth under salt stress through ROS-mediated modulation of auxin distribution. Front Plant Sci 10:522. https://doi.org/10.3389/fpls.2019.00522

Fujii H, Verslues PE, Zhu JK (2011) Arabidopsis decuple mutant reveals the importance of SnRK2 kinases in osmotic stress responses in vivo. Proc Natl Acad Sci U S A 108(4):1717-1722. https://doi.org/10.1073/pnas.1018367108

Galvan-Ampudia CS, Testerink C (2011) Salt stress signals shape the plant root. Curr Opin Plant Biol 14(3):296-302. https://doi.org/10.1016/j.pbi.2011.03.019

Genisel M, Erdal S, Kızlkaya M (2014) The mitigating effect of cysteine on growth inhibition in salt-stressed barley seeds is related to its own reducing capacity rather than its effects on antioxidant system. Plant Growth Regul 75(1):187197. https://doi.org/10.1007/s10725-014-9943-7

Gibeaut DM, Carpita NC (1991) Tracing cell wall biogenesis in intact cells and plants: selective turnover and alteration of soluble and cell wall polysaccharides in grasses. Plant Physiol 97(2):551-561. https://doi.org/10.1104/pp.97.2.551

Golldack D, Li C, Mohan H, Probst N (2014) Tolerance to drought and salt stress in plants: unraveling the signaling networks. Front Plant Sci 5:151. https://doi. org/10.3389/fpls.2014.00151

Gong ZH, Xiong LM, Shi HZ, Yang SH, Luis RE, Xu GH, Chao DY, Li JR, Wang PC, Qin F, Li JJ, Ding YL, Shi YT, Wang Y, Yang YQ, Guo Y, Zhu JK (2020) Plant abiotic stress response and nutrient use efficiency. Sci China Life Sci 63(5): 635-674. https://doi.org/10.1007/s11427-020-1683-x

Harholt J, Suttangkakul A, Vibe Scheller H (2010) Biosynthesis of pectin. Plant Physiol 153(2):384-395. https://doi.org/10.1104/pp.110.156588

Hasegawa PM, Bressan RA, Zhu J-K, Bohnert HJ (2000) Plant cellular and molecular responses to high salinity. Annu Rev Plant Physiol Plant Mol Biol 51(1):463-499. https://doi.org/10.1146/annurev.arplant.51.1.463

Hazman M, Hause B, Eiche E, Nick P, Riemann M (2015) Increased tolerance to salt stress in OPDA-deficient rice ALLENE OXIDE CYCLASE mutants is linked with an increased ROS-scavenging activity. J Exp Bot 66(11):3339-3352. https://doi.org/10.1093/jxb/erv142

Hu H, Brown PH (1994) Localization of boron in cell walls of squash and tobacco and its association with pectin (evidence for a structural role of boron in the Cell Wall). Plant Physiol 105(2):681-689. https://doi.org/10.11 04/pp.105.2.681

Hu R, Zhu Y, Wei J, Chen J, Shi H, Shen G, Zhang H (2017) Overexpression of PP2A$\mathrm{C} 5$ that encodes the catalytic subunit 5 of protein phosphatase $2 \mathrm{~A}$ in Arabidopsis confers better root and shoot development under salt conditions. Plant Cell Environ 40(1):150-164. https://doi.org/10.1111/pce.12837

Lin CC, Kao CH (1996) Proline accumulation is associated with inhibition of rice seedling root growth caused by NaCl. Plant Sci 114(2):121-128. https://doi. org/10.1016/0168-9452(96)04323-3

Lin CC, Kao CH (2001) Cell wall peroxidase activity, hydrogen peroxide level and $\mathrm{NaCl}$-inhibited root growth of rice seedlings. Plant Soil 230(1):135-143. https://doi.org/10.1023/A:1004876712476

Liu PR, Wu WH (1999) Physiological mechanisms of growth inhibition by concentrated potassium in Dunaliella Salina. J Integr Plant Biol 41(6):617-623 https://www.jipb.net/EN/Y1999/N41//6/

Liu W, Li RJ, Han TT, Cai W, Fu ZW, Lu YT (2015) Salt stress reduces root meristem size by nitric oxide-mediated modulation of auxin accumulation and signaling in Arabidopsis. Plant Physiol 168(1):343-356. https://doi.org/10.11 04/pp.15.00030

Malamy JE, Ryan KS (2001) Environmental regulation of lateral root initiation in Arabidopsis. Plant Physiol 127(3):899-909. https://doi.org/10.1 104/pp.127.3.899

Match T (1997) Boron in plant cell walls. Plant Soil 193:59-70. https://doi.org/10.1 023/A:1004207824251

McNeil M, Darvill AG, Fry SC, Albersheim P (1984) Structure and function of the primary cell walls of plants. Annu Rev Biochem 53(1):625-663. https://doi. org/10.1146/annurev.bi.53.070184.003205

Mertz RA, Olek AT, Carpita NC (2012) Alterations in cell-wall glycosyl linkage structure of Arabidopsis murus mutants. Carbohydr Polym 89(2):331-339. https://doi.org/10.1016/j.carbpol.2012.02.044 
Moldovan L, Moldovan NI (2004) Oxygen free radicals and redox biology of organelles. Histochem Cell Biol 122(4):395-412. https://doi.org/10.1007/s0041 8-004-0676-y

O'Neill MA, Eberhard S, Albersheim P, Darvill AG (2001) Requirement of borate cross-linking of cell wall rhamnogalacturonan II for Arabidopsis growth. Science 294(5543):846-849. https://doi.org/10.1126/science.1062319

O'Neill MA, Ishii T, Albersheim P, Darvill AG (2004) Rhamnogalacturonan II: structure and function of a borate cross-linked cell wall pectic polysaccharide. Annu Rev Plant Biol 55(1):109-139. https://doi.org/10.1146/a nnurev.arplant.55.031903.141750

Petricka JJ, Winter CM, Benfey PN (2012) Control of Arabidopsis root development. Annu Rev Plant Biol 63(1):563-590. https://doi.org/10.1146/a nnurev-arplant-042811-105501

Phang TH, Shao G, Lam HM (2008) Salt tolerance in soybean. J Integr Plant Biol 50(10):1196-1212. https://doi.org/10.1111/j.1744-7909.2008.00760.x

Rahnama A, Munns R, Poustini K, Watt M (2011) A screening method to identify genetic variation in root growth response to a salinity gradient. J Exp Bot 62(1):69-77. https://doi.org/10.1093/jxb/erq359

Ranocha P, Dima O, Nagy R, Felten J, Corratgé-Faillie C, Novák O, Morreel K, Lacombe B, Martinez Y, Pfrunder S, Jin X, Renou JP, Thibaud JB, Ljung K, Fischer U, Martinoia E, Boerjan W, Goffner D (2013) Arabidopsis WAT1 is a vacuolar auxin transport facilitator required for auxin homoeostasis. Nat Commun 4(1):2625. https://doi.org/10.1038/ncomms3625

Tomas R, Fernanda GV, Antonio OJ (2020) Auxin-mediated responses under salt stress: from developmental regulation to biotechnological applications. J Exp Bot 71(13):3843-3853. https://doi.org/10.1093/jxb/eraa241

Rodriguez HG, Roberts J, Jordan WR, Drew MC (1997) Growth, water relations, and accumulation of organic and inorganic solutes in roots of maize seedlings during salt stress. Plant Physiol 113(3):881-893. https:/doi.org/10.1104/pp.113.3.881

Roy SJ, Negrão S, Tester M (2014) Salt resistant crop plants. Curr Opin Biotechnol 26:115-124. https://doi.org/10.1016/j.copbio.2013.12.004

Shelden MC, Roessner U (2013) Advances in functional genomics for investigating salinity stress tolerance mechanisms in cereals. Front Plant Sci 4:123. https://doi.org/10.3389/fpls.2013.00123

Shi H, Kim Y, Guo Y, Stevenson B, Zhu JK (2003) The Arabidopsis SOS5 locus encodes a putative cell surface adhesion protein and is required for normal cell expansion. Plant Cell 15(1):19-32. https://doi.org/10.1105/tpc.007872

Suzuki N, Koussevitzky S, Mittler R, Miller G (2012) ROS and redox signalling in the response of plants to abiotic stress. Plant Cell Environ 35(2):259-270. https:// doi.org/10.1111/j.1365-3040.2011.02336.x

Tsukagoshi H (2012) Defective root growth triggered by oxidative stress is controlled through the expression of cell cycle-related genes. Plant Sci 197: 30-39. https://doi.org/10.1016/j.plantsci.2012.08.011

Wang Y, Li K, Li X (2009) Auxin redistribution modulates plastic development of root system architecture under salt stress in Arabidopsis thaliana. J Plant Physiol 166(15):1637-1645. https://doi.org/10.1016/j.jplph.2009.04.009

Wolf S, Hématy K, Höfte H (2012) Growth control and cell wall signaling in plants. Annu Rev Plant Biol 63(1):381-407. https://doi.org/10.1146/annurev-arplant042811-105449

Wu SJ, Ding L, Zhu JK (1996) SOS1, a genetic locus essential for salt tolerance and potassium acquisition. Plant Cell 8(4):617-627. https://doi.org/10.1105/tpc.8.4.617

Yang L, Zhang J, He J, Qin Y, Hua D, Duan Y, Chen Z, Gong Z (2014) ABAmediated ROS in mitochondria regulate root meristem activity by controlling PLETHORA expression in Arabidopsis. PLoS Genet 10(12):e1004791. https:// doi.org/10.1371/journal.pgen.1004791

Yang Y, Guo Y (2018) Unraveling salt stress signaling in plants. J Integr Plant Biol 60(9):796-804. https://doi.org/10.1111/jipb.12689

Yao SX, Chen SS, Xu DS, Lan HY (2010) Plant growth and responses of antioxidants of Chenopodium album to long-term $\mathrm{NaCl}$ and $\mathrm{KCl}$ stress. Plant Growth Regul 60(2):115-125. https://doi.org/10.1007/s10725-009-9426-4

Yuan HM, Xu HH, Liu WC, Lu YT (2013) Copper regulates primary root elongation through PIN1-mediated auxin redistribution. Plant Cell Physiol 54(5):766-778. https://doi.org/10.1093/pcp/pct030

Zhao C, Zayed O, Zeng F, Liu C, Zhang L, Zhu P, Hsu CC, Tuncil YE, Tao WA, Carpita NC, Zhu JK (2019) Arabinose biosynthesis is critical for salt stress tolerance in Arabidopsis. New Phytol 224(1):274-290. https://doi.org/10.1111/nph.15867

Zhao KF, Fan H, Harris PJC (1995) The physiological basis of growth inhibition of halophytes by potassium. J Integr Plant Biol 37(6):437-442 https://www.jipb. net/EN/Y1995/N37/16/
Zhong H, LÄUchli A (1993) Spatial and temporal aspects of growth in the primary root of cotton seedlings: effects of $\mathrm{NaCl}$ and $\mathrm{CaCl}_{2}$. J Exp Bot 44:763771. https://doi.org/10.1093/jxb/44.4.763

Zhu J, Fu X, Koo YD, Zhu JK, Jenney FE Jr, Adams MW, Zhu Y, Shi H, Yun DJ, Hasegawa PM, Bressan RA (2007) An enhancer mutant of Arabidopsis salt overly sensitive 3 mediates both ion homeostasis and the oxidative stress response. Mol Cell Biol 27(14):5214-5224. https://doi.org/10.1128/MCB.01989-06

Zhu J, Lee BH, Dellinger M, Cui X, Zhang C, Wu S, Nothnagel EA, Zhu JK (2010) A cellulose synthase-like protein is required for osmotic stress tolerance in Arabidopsis. Plant J 63(1):128-140. https://doi.org/10.1111/j.1365-313X.2010.04227.x

Zhu JK (2003) Regulation of ion homeostasis under salt stress. Curr Opin Plant Biol 6(5):441-445. https://doi.org/10.1016/s1369-5266(03)00085-2

\section{Publisher's Note}

Springer Nature remains neutral with regard to jurisdictional claims in published maps and institutional affiliations. 